\title{
MEC-BRASIL, DECRETO 10.502. Política Nacional de Educação Especial: Equitativa, Inclusiva e com Aprendizado ao Longo da Vida, de 30 de setembro de 2020. Brasília: MEC, 2020.
}

\author{
Cristina Miyuki Hashizume \\ Doutora em Psicologia Escolar e do Desenvolvimento Humano (IPUSP) \\ Universidade Metodista de São Paulo-UMESP \\ São Paulo - SP - Brazil \\ cristina.mhashizume@gmail.com
}

Para citar- (ABNT NBR 6023:2018)

HASHIZUME, Cristina Miyuki. Resenha. Eccos - Revista Cientifica, São Paulo, n. 56, p. 1-7, e18627, jan./mar., 2021. Resenha da obra de MEC-Brasil, decreto 10.502. Política nacional de educação especial: equitativa, inclusiva e com aprendizado ao longo da vida, de 30 de setembro de 2020. Brasília: MEC, 2020. https://doi.org/10.5585/eccos.n56.18627.

Resenharemos o conteúdo do Decreto 10.502, a partir das perspectivas da sociedade

civil, acadêmica e jurídica e do controle social no debate democrático sobre direitos e inclusão. O documento é composto por dezoito artigos, sendo que os últimos sete tratam das disposições finais e se referem a ações mais práticas de operacionalização das diretrizes que são apresentadas ao longo do documento. É assinado pela Presidência da República e pelos Ministérios da Educação (MEC) e da Mulher, da Família e dos Direitos Humanos (MMFDH).

Manifestos produzidos por diferentes instituições que estudam e militam em prol da inclusão escolar publicaram na primeira semana após o decreto importantes documentos. Analisamos, para essa resenha, os documentos emitidos pelos: Sindicato dos Servidores Públicos das Secretarias de Educação e de Cultura do Estado do Ceará (APEOC), Associação Nacional dos Membros do Ministério Público de Defesa dos Direitos das Pessoas com Deficiência e Idosos (AMPID), a Campanha Nacional pelo Direito à Educação, o Laboratório de Estudos e Pesquisas em Ensino e Diferença (LEPED/FE/UNICAMP), a Comissão de Proteção aos Direitos da Pessoa com Deficiência da Ordem dos Advogados do Brasil (Seção Pará), a Associação Brasileira para Ação pelos Direitos das Pessoas Autistas (ABRAÇA), o Conselho Regional (CRP-SP) e Federal de Psicologia (CFP) e a Associação Brasileira de Pesquisadores em Educação Especial (ABPEE/ANPED). A partir de tais documentos, assim como de autores consagrados no debate da educação inclusiva, discutiremos preliminarmente o documento como um todo, assim como as notas emitidas pelas instituições de impacto no cenário nacional na primeira semana após instituído o decreto. 
O documento da APEOC aponta a "retomada de escolas e classes especiais para alunos com deficiência", modelo já superado por diversos tratados internacionais, que têm posicionamento consolidado sobre a maior efetividade da inclusão em escolas regulares que tenham uma abordagem diferenciada à diferença. Também ressalta que o anunciado poder de "escolha" das famílias em matricular ou não seus filhos em uma escola regular funcionará como um dispositivo a mais para gestores alegarem não estar preparados para a inclusão. Este último aspecto parece ser o ponto mais relevante do decreto, já que privatiza a escolha pela formação do aluno com deficiência, deixando, portanto, de ser obrigação do estado o oferecimento de uma educação inclusiva pública e universal.

O documento da AMPID também faz referência às conquistas da Convenção sobre os Direitos das Pessoas com Deficiência e à Lei $\mathrm{n}^{\circ}$ 13.146/2015 (BRASIL, 2015), desconsideradas pelo decreto, "em flagrante retrocesso às conquistas obtidas em relação ao direito humano à Educação Inclusiva".

A Campanha Nacional pelo Direito à Educação enfoca que o atual decreto "ignora compromissos internacionais de que o país é signatário de documentos que pugnam pela inclusão, incondicionalmente", contrapondo-se ao artigo 208 da Constituição, que discorre sobre o "atendimento educacional aos portadores de deficiência, preferencialmente na rede regular de ensino". Segundo a organização, os adjetivos "equitativo" e "inclusivo" que constam no decreto são utilizados de maneira diferente do proposto pela ONU, ressaltando que, em verdade, a equidade é o movimento de diferenciar estratégias para gerar inclusão e participação nos espaços comuns de convívio, o oposto da proposta que se apresenta no Decreto.

A Carta emitida pelo LEPED ressalta no decreto a apropriação de termos importantes já exaustivamente debatidos ao longo da história da educação inclusiva, assim como uma proposição de "nova" política de educação especial, que, na verdade, se configura como mera reforma, trazendo de volta "práticas outrora fracassadas" no passado. Revelam a fragilidade do documento, que usa "argumentações tendenciosas e mal embasadas por estudos e posicionamentos" que se "contrapõem aos avanços e esforços despendidos por familiares e educadores, em todo o território nacional, que aderiram às diretrizes da Política Nacional de Educação Especial na Perspectiva da Educação Inclusiva (PNEEPEI/2008)". A carta também demonstra preocupação com a intencionalidade das recentes políticas públicas em terceirizar a Educação Especial, explícita nas entrelinhas do documento, de alocar recursos públicos em instituições privadas, em detrimento da continuidade e ampliação dos investimentos na escola pública. 
O documento da Comissão de Proteção aos Direitos da Pessoa com Deficiência da $O A B$ - Pará alega que o decreto prega "a diferenciação curricular, segrega o ensino e as pessoas da sala de aula, não encontra respaldo jurídico nas diretrizes da LBI e outras legislações anteriores", trazendo distorções conceituais em relação à educação inclusiva e outras problematizações graves, que iremos discutir a seguir (FERRARI, 2020).

$\mathrm{O}$ decreto abre possibilidade de financiamento não estatal e privado de classes especializadas em escolas ditas inclusivas e de escolas especializadas. Assim, é contraditório reconhecer que instituições inclusivas possam ter classes especializadas e que sistemas de ensino inclusivos sejam compostos por entidades especializadas.

Ao mesmo tempo, o decreto defende que os ambientes de aprendizagem sejam os "menos restritivos possíveis" diante das inadequações do aluno, sugerindo que família e equipe multidisciplinar possam optar por uma "alternativa educacional mais adequada", ao mesmo tempo que assume que definirá critérios para determinar quais são os "educandos que não se beneficiam das escolas regulares inclusivas", como se não houvesse, de fato, escolha.

Do mesmo modo, propõe que a comunidade escolar possa decidir sobre a inserção do aluno em classes especializadas e, ainda não reconhece o caráter complementar e suplementar do Atendimento Educacional Especializado (AEE), descaracterizando-o e defendendo que este possa ser substituto do ensino regular, propondo que semelhantes convivam com semelhantes.

O artigo 7 do Decreto cita "outros serviços e recursos para atender os educandos da educação especial" sem especificar quais são, deixando "brecha para que verbas destinadas à educação financiem outros tipos de serviços não educacionais, inclusive terapêuticos", o que sobrepõe o direito universal à saúde ao da educação. Ao se referir aos "educandos que não se beneficiam das escolas regulares inclusivas", a política tira o foco das barreiras existentes e atribui ao educando com deficiência a qualidade de estar ou não apto a frequentar um determinado espaço, atribuindo ao aluno a culpabilidade pela sua deficiência. O Decreto menciona o aprendizado ao longo da vida e não trata da transversalidade da educação especial desde a Educação Infantil até a Educação Superior, da Educação de Jovens e Adultos ou da Educação Técnica e Profissionalizante.

Além disso, há uma limitação da função de prestadora de serviços/produtora de conhecimento sobre deficiência à universidade, o que não inclui, necessariamente, pessoas com deficiência. Não considera a implementação das cotas e dos núcleos de inclusão e acessibilidade dos estudantes universitários com deficiência, desconsiderando a Convenção dos Direitos da Pessoa com Deficiência (CDPD), que garante o aprendizado ao longo da vida 
sem exclusão. A definição de aprendizado ao longo da vida adotada no Decreto, em que "a educação não acontece apenas no âmbito escolar", trata-se de um aspecto verdadeiro, porém, não é papel do Estado, o que pode desobrigar o governo a regulamentar as provisões (da CDPD) que asseguram, por exemplo, acesso ao Ensino Superior em geral, treinamento profissional, educação para adultos e formação continuada sem discriminação e com igualdade de condições.

A atual proposta rompe com as políticas já existentes, alinhadas às diretrizes internacionais de garantia de direitos às pessoas com deficiência. Também aponta para um olhar neoliberal sobre serviços educacionais que seriam oferecidos livremente, sem fazer referência às parcerias com instituições jurídicas sem fins lucrativos, o que indica a prevalência de um projeto privatista para o atendimento escolar e de outras atividades especiais voltadas às pessoas com deficiência no Brasil. Essa rede de interesses comerciais dá ao documento o contexto a partir do qual ele deve ser analisado.

A ABPE/ANPED explicita sua preocupação com o detalhamento das deficiências e dos diagnósticos e serviços especializados complementares terceirizados já que se tratam de uma abertura para a entrada de instituições fora da rede oficial de ensino. Tais empresas, especializadas no oferecimento de serviços privados, podem ratificar o segregacionismo, repetindo o que historicamente já ocorreu na educação especial: retrocedermos a uma visão "classificatória e nosográfica que patologiza e medicaliza esses alunos", dando uma "suposta liberdade de escolha da família". Estudos mostram que, com a melhor das intenções, a proposta de um modelo inclusivo pode se desdobrar em práticas excludentes, que segregam mais do que promovem inclusão. A obrigação do MEC no compromisso em relação à comunidade escolar que vive a inclusão deve ser de uma educação de qualidade, social, integral e humanizada.

O ensino ao longo da vida, perspectiva educacional apresentada já desde o título do documento, trata-se de um modo de pensar educação a partir de parâmetros liberais de aprendizagem. Da forma como é usado no decreto, desconsidera políticas conquistadas ao longo das últimas décadas, assim como ao se referir ao ensino básico, considera da Educação Infantil até o Ensino Médio nas diretrizes propostas de aplicação de ensino especial e deposita no Ensino Superior a competência de produzir conhecimento sobre a deficiência, o que vai de encontro com o necessário protagonismo dos alunos com deficiência e a necessidade de se ouvir a voz autoral desse grupo na construção de políticas que lhes sejam benéficas. A consulta às pessoas com deficiência, por meio de suas organizações representativas, é essencial no processo de elaboração de legislações e políticas relacionadas às pessoas com deficiência, processo que parece não ter sido respeitado na escrita desse decreto. 
Há um tom no documento que legitima conhecimentos especializados fora da escola, que podem esvaziar ainda mais o saber-fazer docente e canalizar para fora da escola o papel preventivo e de tratamento aos alunos com deficiência, numa vigilância perene, ao longo da vida. O life long learning apoia o conceito de "aprender a aprender", valorizando o conhecimento polivalente em diferentes áreas, reinserindo o aluno com deficiência, primeiramente, às exigências de mercado. Um estudo internacional elencou as seguintes categorias para descrever tal abordagem: habilidades, currículo, emoções, tecnologia, dimensão espiritual, ensino, gestão escolar e cultura institucional (CHIAPPE et al, 2020). Nesse sentido, apresentam-se como um "paradigma renovado" e mais eficiente contra a tradição e modelos usados desde o século XIX, sem êxito.

Em se tratando de uma discussão acerca de saberes especializados sobre a deficiência, vemos uma tendência a "autorizar" algumas áreas a produzir conhecimento sobre a questão, o que pode se tornar um agravante para o trabalho do professor de salas regulares, que passa a ter seu saber-fazer deslegitimado junto aos alunos. O especialismo acaba por se sobrepor em relação a saberes tão ou mais importantes para o processo de ensino-aprendizagem, acirrando uma disputa por conhecimentos especializados que acabam por assumir para si a expectativa de atingir os objetivos que o saber docente, tão deslegitimado, não consegue.

Em linhas gerais, o documento demonstra o negacionismo dos avanços conquistados nas últimas décadas, sejam leis, notas técnicas ou o conhecimento científico já evidenciado em pesquisas. É visível os jogos de poder que subjazem o debate da escola especial e da escola regular inclusiva: envolvem terceirização de serviços especializados, além da movimentação de uma indústria de cursos, empresas e assessorias que atuarão sobre os diagnósticos, tratamentos e investimentos em áreas do saber especializadas. Chama atenção também a disputa pelo status de saber mais legitimado para atuar na educação especial/ inclusiva, desconsiderando-se a responsabilidade da rede educacional nacional com uma educação para todos, em salas regulares e sem segregação de alunos.

O decreto retoma termos já superados em debates sobre a área em nível internacional, sob o risco de se romper com o direito do futuro cidadão com deficiência ter seu lugar protagonista de sujeito de direitos e deveres, garantido nas últimas décadas pelas políticas públicas afirmativas. 


\section{Referências}

ABRAÇA. Nota de repúdio ao decreto 10520/2020. Disponível em: https://abraca. net.br/manifesto-de-repudio-ao-decreto-no-10-502-2020/. Acesso 08 out 2020.

APEOC. Nota de repúdio: não à exclusão de alunos com deficiência nas escolas regulares. Disponível em: https://apeoc.org.br/nota-de-repudio-nao-a-exclusao-de-alunos-comdeficiencia-nas-escolas-regulares/\#: :text=Selecione $\% 20 \mathrm{a} \% 20 \mathrm{p} \% \mathrm{C} 3 \%$ A1 gina,NOTA\%20DE\%20REP\%C3\%9ADIO $\% 3 \mathrm{~A} \% 20 \mathrm{~N} \% \mathrm{C} 3 \% 83 \mathrm{O} \% 20 \% \mathrm{C} 3 \% 80 \% 20 \mathrm{EXCLUS} \% \mathrm{C}$ 3\%830\%20DE,COM\%20DEFICI\%C3\%8ANCIA \%20NAS\%20ESCOLAS\%20REGULARE S\&text $=$ O \%20Sindicato $\% 20$ APEOC $\% 20$ vem $\% 20$ por,30\%20de $\% 20$ setembro $\% 20 \mathrm{de} \% 202020$ .Acesso 08 out 2020.

AMPID, Política Nacional de Educação Especial: Equitativa, Inclusiva e com Aprendizado ao Longo da Vida. Disponível em: https://ampid.org.br/site2020/?p=9816. Acesso 08 out 2020.

BRASIL. Ministério da Educação. Secretaria de Educação Especial. Política Nacional de Educação Especial na Perspectiva da Educação Inclusiva. Brasília: MEC/ SEED, 2008. BRASIL. Estatuto da pessoa com deficiência/ Lei $n^{\circ} 13.146 / 2015$. Brasília: Senado Federal, Coordenação de Edições Técnicas, 2015. 65 p.

Campanha ao direito à educação (Org.). Carta à sociedade. Disponível em: https:// campanha.org.br/noticias/2020/10/02/carta-a-sociedade-brasileira-decreto-n-105022020-queinstitui-a-politica-nacional-de-educacao-especial-equitativa-inclusiva-e-com-aprendizado-aolongo-da-vida/ Acesso 08 out 2020.

CONSELHO REGIONAL DE PSICOLOGIA (SP). Carta de repúdio ao Decreto 10502. Disponível em: https://bit.ly/2I2A3zL .

CONSELHO REGIONAL DE PSICOLOGIA (SP). Nota técnica. "Orientações sobre a atuação dos psicólogos no atendimento com pessoas com deficiência. São Paulo: CRP, 2019. Disponível em: https://crpsp.org/uploads/legislacao/1620/WBHY4Om6mQvksJRf3 tSARinJVdl2wCpt.pdf . Acesso 08 out 2020.

CONSELHO FEDERAL DE PSICOLOGIA. Mudança na Política de Educação Especial é retrocesso e segregação! Disponível em: https://site.cfp.org.br/mudanca-na-politica-deeducacao-especial-e-retrocesso-e-segregacao-entenda-posicionamento-do-cfp/ Acesso 08 out 2020.

CHIAPPE, Andrés et al. Rethinking 21st century schools: the quest for lifelong learning ecosystems. Ensaio: aval.pol.públ.Educ., Rio de Janeiro, v.28, n.107, p. 521-

544, June 2020. 
FERRARI, D. Cada um no seu quadrado de arama farpado. Disponível em:

https://www.seculodiario.com.br/educacao/cada-um-no-seu-quadrado-de-arame-farpadocritica-professor-da-ufes. Acesso 08 out 2020.

LEPED. Carta-convocação do LEPED. Disponível em https://inclusaoja.com.br/

2020/10/01/carta-convocacao-do-leped-contra-a-destruicao-da-inclusao-no-brasil/. Acesso 08 out 2020 .

OAB- PA. Nota de repúdio. Disponível em: http://www.oabpa.org.br/ index.php/noticias/7516-comissao-de-pcd-repudia-nova-politica-de-educacao-especial-dogoverno-federal. Acesso 08 out 2020. 